\title{
A Finite Element Analysis of a Biodegradable Cervical Plate and Screw System
}

\author{
Jaeyon Choi, Lihua Che, Keung Nyun Kim, Seong Yi, Yoon Ha, Do Heum Yoon, Dong Ah Shin ${ }^{凶}$ \\ Department of Neurosurgery, Severance Hospital, Yonsei University College of Medicine, Seoul, Korea
}

\begin{abstract}
Objective: To evaluate a biodegradable cervical plate and screw system by 3D modeling and finite element analysis. Methods: The authors are developing a biodegradable cervical plate and screw system using poly-L-lactic acid (PLLA). A computational model was evaluated before experimenting it into humans. The system was fabricated using 3D modeling and analyzed with finite element analysis using a commercially available software (Abaqus 6.4, Simulia, USA). Compression and bending tests were performed by applying a force of $100 \mathrm{~N}$ to the screw to analyze the applied von Mises stress. The screw and plate were combined, and a force of $100 \mathrm{~N}$ was applied to the screw to analyze the von Mises stress on the screw and plate. Results: When a bending force of 100 $\mathrm{N}$ was applied to the distal $1 / 3$ part of the screw, widening of the head and anchor of the screw, bending of approximately $20^{\circ}$, and concentration of von Mises stress at the pin were observed. These phenomena indicate the possibility of head and anchor fractures when severe loading is applied. When a compressive force of $100 \mathrm{~N}$ was applied to the screw in the plate and screw combined model, concentration of von Mises stress at the blocking parts of the plate. The phenomenon indicate the possibility of plate fracture when severe loading is applied. Conclusion: Because biodegradable material is weak, biomechanical weakness may result in breakage of a system. According to our research, two parts of screw should be combine into one and the plate design also be modified without weak points.
\end{abstract}

Key Words: Biodegradable materials; Spinal implant; Finite element analysis; Biomechanics; Anterior cervical discectomy and fusion

$\triangle$ Corresponding Author: Dong Ah Shin, Department of Neurosurgery, Spine and Spinal Cord Institute, Yonsei University College of Medicine, 50-1 Yonsei-ro, Seodaemun-gu, Seoul 03722, Korea. Tel: +82-2-2228-2174, Fax: +82-2-393-9979 E-mail: cistern@yuhs.ac

\section{INTRODUCTION}

The finite element method is widely used to observe biomechanical changes after implantation of spinal implants ${ }^{14}$. In case of a cadaver esperiment, it is difficult to repeat the exactly same experiment and more cadavers are required. However, for finite element analysis, it is possible to produce several surgical models with one finite element model $^{10)}$. In addition, we can perform comparative experiments under the exactly same condition, unlike in cadaveric studies. It is also easy to measure joint contact force or stress applied to the ligament, which is difficult to measure when the experiment is carried out with a cadaver. The analysis results can be reliable when the finite element model is verified against the cadaveric study $^{6,11)}$.

Anterior cervical discectomy and fusion is a common technique that has been used for decades to treat degenerative cervical disease since it has a high fixation force and can preserve the original disc height and maintain spine stability ${ }^{1,15)}$. However, the thickness of the plate used may lead to problems such as foreign body sensation and dysphagia after surgery, side effects of titanium allergic reaction, and image distortion in MRI ${ }^{12,13)}$. Therefore, biodegradable cervical plates and screws that will disintegrate after use seem necessary ${ }^{4,5,9)}$.

The purpose of this study was to analyze the biomechanical properties of a biodegradable cervical plate and screw system using finite element analysis and to ascertain its safety and effectiveness before use in the human body.

\section{MATERIALS AND METHODS}

\section{Creating 3D Models}

The screw and plate were produced using 3D modeling software. The plate was $22 \mathrm{~mm}$ long, $16 \mathrm{~mm}$ wide, and $2 \mathrm{~mm}$ thick, and the screw length was $16 \mathrm{~mm}$. The plate and screw are manufactured in various sizes, but this finite element analysis involved a 22-mm long plate and a $16-\mathrm{mm}$ long screw, which are commonly used clinically. The screw consists of a head, an anchor, and two pins connecting them. The head is made of biodegradable material, and the pin and anchor are made of titanium. The head of the screw is rotatable about the axis of the anchor, which is locked by inserting the screw into the hole of the plate and turning the head. 


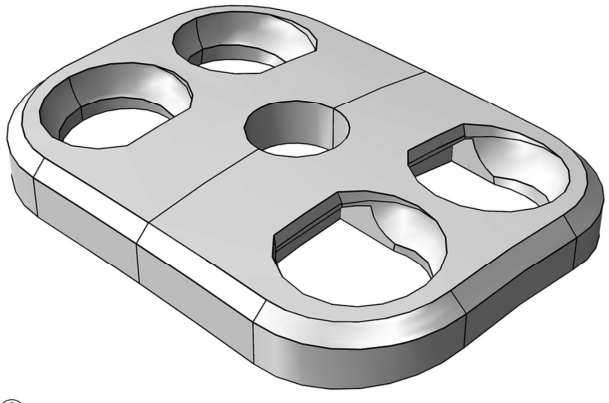

(A)

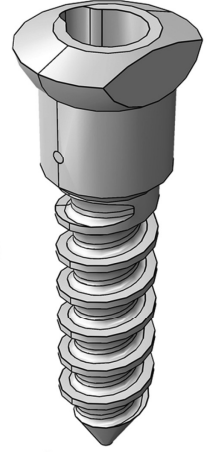

(B)

Fig. 1. Biodegradable plate (A) and screw (B) produced by 3D modeling. The screw consists of head, pin, and anchor. The screw consists of a head, an anchor, and two pins connecting them.

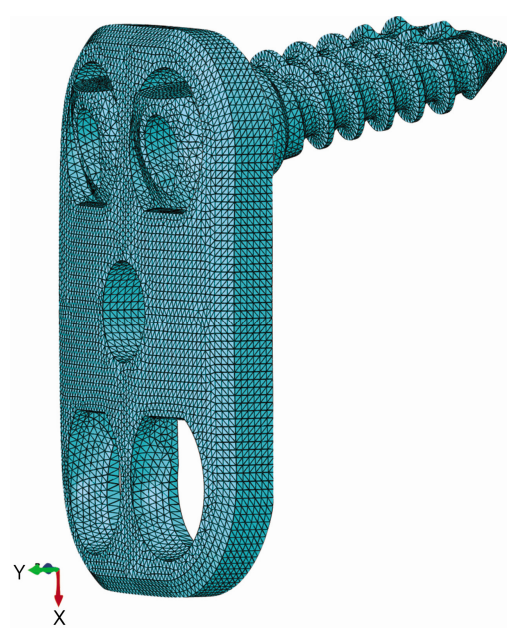

Fig. 2. Mesh is composed of C3D10 tetra mesh.

\section{Finite Element Model}

A 3D linear FE model of the cervical plate and screw system was developed. Abaqus (Dassault System, Paris, France) was used to simulate surgical scenarios with the spine model. The 3D model was loaded into the STEP format by Abaqus, the finite element analysis software. The FE model consisted of 4 cervical screws and 1 cervical plate (Fig. 1\&2). The screws and plate were made of tetrahedral elements. Facet contact surface and endplates were made of hexahedral elements with $1 \mathrm{~mm}$ thickness. Surface-to-surface contact was used to simulated the interaction between the contacting surfaces of facet joints. Then, 3 models were analyzed: (1) screw-only model, (2) 1/4-sized model with one hole and screw, and (3) 1/2-sized model with two holes and screws. Model 2 was a preliminary experiment conducted to capture the proper condition of Model 3. The properties of all elements were assigned as previous literatures. Linear elasticity was applied to all elements. Titanium was alloy-dependent, but young modulus was 100,000 MPa Poisson ratio was 0.30 . The young modulus of PLLA was $4,000 \mathrm{MPa}$ and the Poisson ratio is 0.3 (Table 1$)^{8)}$.

Table 1. Material properties of parts

\begin{tabular}{lccrr}
\hline & $\begin{array}{c}\text { Young's modulus } \\
\text { (Nmm-2) }\end{array}$ & $\begin{array}{r}\text { Poisson's } \\
\text { coefficient }\end{array}$ & $\begin{array}{r}\text { Number of } \\
\text { elements }\end{array}$ & $\begin{array}{r}\text { Type of } \\
\text { elements }\end{array}$ \\
\hline Plate & 4,000 & 0.3 & 105,613 & C3D10 \\
Screw head & 4,000 & 0.3 & 15,109 & C3D10 \\
Screw pin & 100,000 & 0.3 & 170 & C3D10 \\
Screw anchor & 100,000 & 0.3 & 32,811 & C3D10 \\
\hline
\end{tabular}
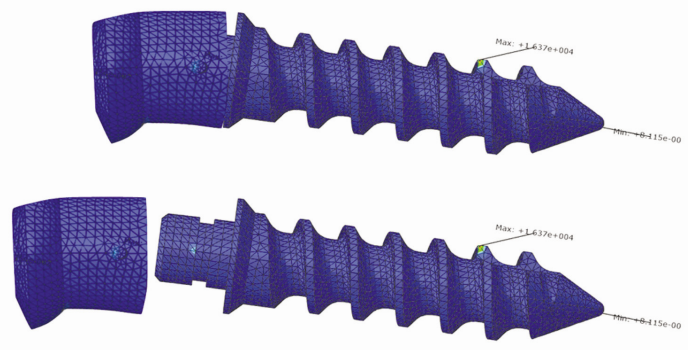

(B)
(A)
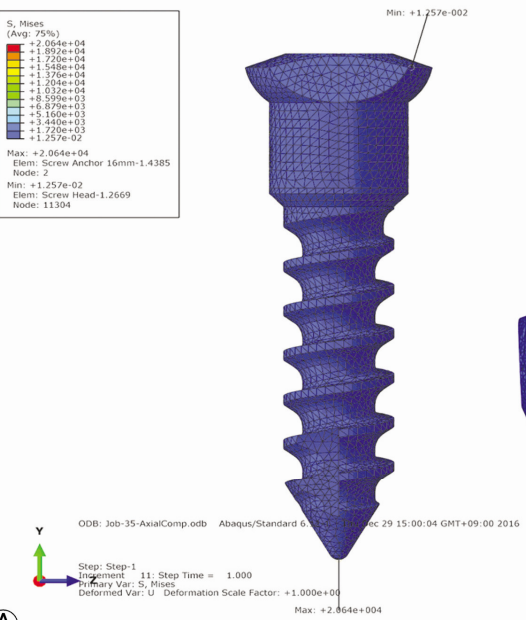

Fig. 3. When $100 \mathrm{~N}$ axial compression was applied to the screw (A), concentration of von Mises stress was not observed. When a bending force is applied to the distal $1 / 3$ point of the screw (B), von Mises stress is concentrated on the pin connecting the anchor and the head, and deformation of the lower part of the head is also observed. This shows that there is a possibility of head and anchor segmentation when excess loading is applied. 


\section{Finite Element Analysis of the Screw Model}

In the screw only model, the upper surface of the screw head was completely fixed in all directions. To the reference point in a stepwise manner. To reach the target moment, the 10 load steps were applied. The range of motion calculated at the endpoint of the loading cycle was analyzed. To confirm the rigidity of the screw and check the specific occurrence

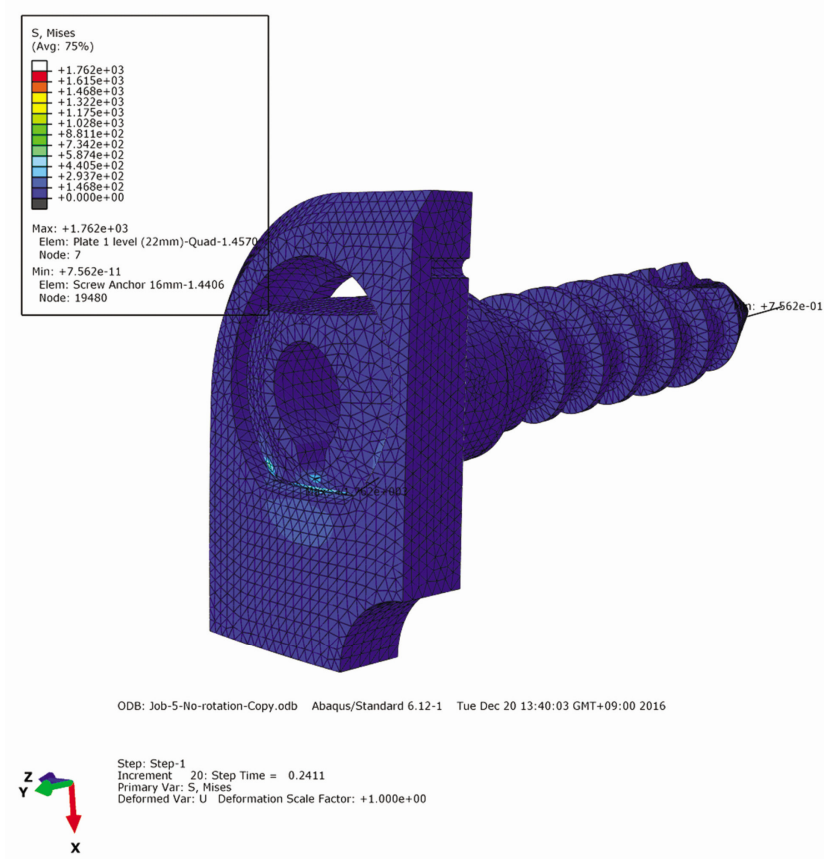

Fig. 4. The 1/4 model, was constructed as preliminary study and Finite element analysis is performed under $1 \mathrm{~mm}$ displacement condition. when a load is applied, finite element analysis was performed. An integral type titanium screw with only titanium parts or a biodegradable screw with only biodegradable parts has a von Mises stress concentration at the portion between screw head and thread when a bending force is applied. However, the present screw can move the head and anchor parts separately, and the two parts have different properties.

\section{Finite Element Analysis of the Screw and Plate Model}

The screw and plate were combined as intended for 3D modeling. The position constraint option of the assembly module was used to combine them. For the convenience of convergence, a tie constraint was applied to the contact surface of the pin, head, and anchor in the coupled model. In order to simulate loading after cervical anterior fusion, a force was applied to displace the entire portion of the head and anchor portion of the screw to $1 \mathrm{~mm}$ below the bone. To establish the simulation conditions, a simpler model, the $1 / 4$ model, was constructed and the finite element analysis was performed. In the $1 / 4$ model, the von Mises stress concentration was observed on the plate hole. To confirm this in the actual model, the $1 / 2$ model was prepared and an encastre condition was applied to the boundary at the lower half of the plate.

\section{RESULTS}

\section{Finite Element Analysis of Screw}

When an axial compression of $100 \mathrm{~N}$ was applied to the tip of the screw, there was no specific motion and the von Mises stress was evenly distributed (Fig. 3A). However, when a
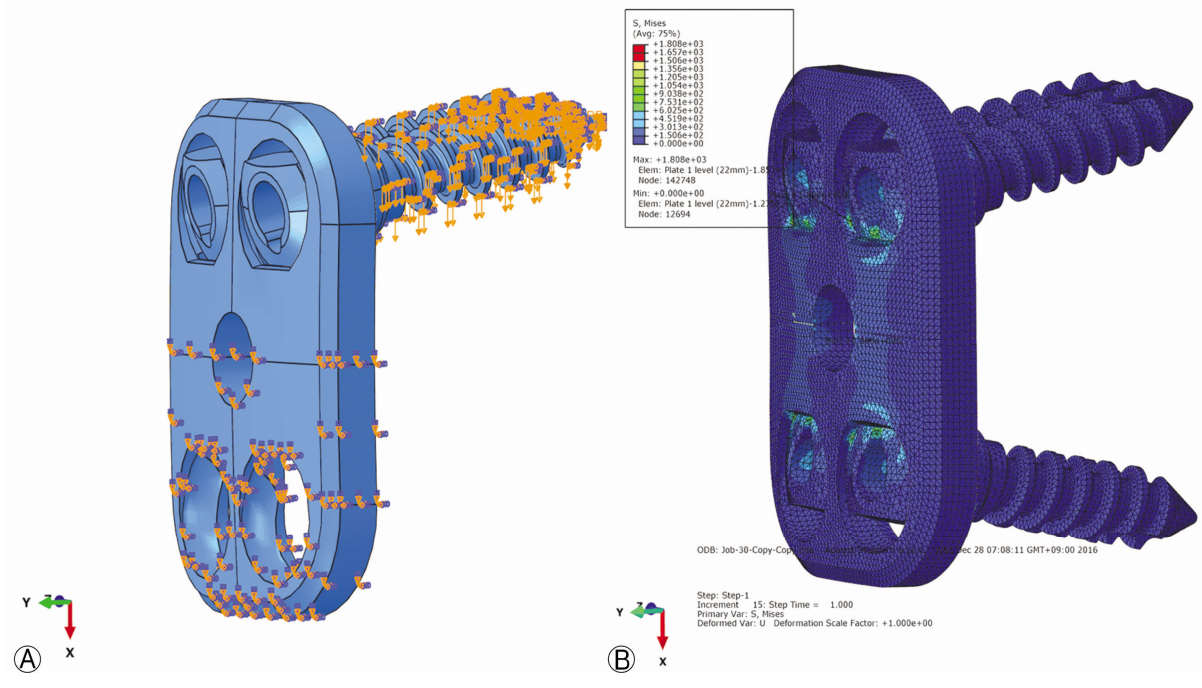

Fig. 5. (A) Boundary condition. (B) Final finite element analysis model. Analyze the von Mises stress by moving the screw vertically by $1 \mathrm{~mm}$. Concentration of von Mises stress was observed on the plate portion of the plate which blocks the screw head. 
bending force of $100 \mathrm{~N}$ was applied to the distal $1 / 3$ point of the screw, widening of the screw head and anchor, bending of approximately $20^{\circ}$, and concentration of von Mises stress at the pin were observed (Fig. 3B). These phenomena strongly indicate the possibility of head and anchor fractures when severe loading is applied. In practice, however, the possibility that the entire portion of the head and anchor of the screw will be subjected to an equal force is rare, so the experimental conditions were considered to represent very severe conditions.

\section{Finite Element Analysis of Screw and Plate Model}

To establish the simulation conditions, a simpler model, the $1 / 4$ model, was constructed and the finite element analysis was performed. In the $1 / 4$ model, the von Mises stress concentration was observed on the plate hole (Fig. 4). To confirm this in the actual model, the 1/2 model was prepared and an encastre condition was applied to the boundary at the lower half of the plate. Final finite element analysis model. Analyze the von Mises stress by moving the screw vertically by $1 \mathrm{~mm}$. Concentration of von Mises stress was observed on the plate portion of the plate which blocks the screw head (Fig. 5). In the final finite element analysis model, we observed von Mises stress concentration on the small plate portion of the plate which prevented the screw from pulling out. This means that plate fracture may occur, so it may be necessary to manipulate the plate to prevent fracture.

\section{DISCUSSION}

Rigid metal plate implants have been associated with a number of potential complications and disadvantages ${ }^{7}$. The efforts to replace bioabsorbable plates to overcome these complications and disadvantages are continuing. We made a biodegradable screw and plate system using 3D modeling software and examined changes in screw and plate when excessive force was applied. As a result of the study, Concentration of von Mises stress was observed on the plate portion of the plate which blocks the screw head and von Mises stress concentration on the small plate portion of the plate which prevented the screw from pulling out. As shown in the finite element analysis above, a break of the head and anchor of the screw can occur when improper force is applied to the screw. When excessive force is applied to the screw in the plate, stress may be concentrated at the portion where the plate and screw head come into contact and fracture may occur.

The results of this study showed that biodegradable cervical plate and screw systems may have mechanical problems if not properly designed. Previous studies have shown possible complications of the biodegradable system. Brkaric $\mathrm{M}$ et al. reported Cracks radiating from and in some cases connecting fatigue striations were clearly visible on the fracture surfaces. Crack initiation began at the sharp interface between the thread and shaft of the screws where the greatest stress concentration is expected to occur ${ }^{3}$. Lebl DR et al. reported that biodegradable cervical plate and screw systems was associated with a high rate of graft extrusion and early loss of intersegmental cervical alignment ${ }^{9}$.

Because of these propertis of biodegradable systems, it tends to favor metal system, but biodegradable systems is expanding gradually. In Tomasino's study, bio-graft subsidence and deformity rates may be higher than those associated with metal implants. But the fusion rate and outcome are comparable to the results achieved with metallic plates. And then safe and carry a low risk of complications. So authors were satisfied with the use of bioabsorbable plates as a reasonable alternative to metal system ${ }^{16)}$. Aryan HE et al. reported that numerous sources have demonstrated fusion rates in excess of $90 \%$ with internal fixation of single-level ACDFs with metallic plates and screws ${ }^{2}$. Therefore, proper mold design is needed to increase the strength, and FE analysis is useful to do it.

There were limitations to our analysis. First, the disadvantages of the finite element analysis model in comparison with in vivo models were not assessed. Second, there was no titanium fixation-based control model. Third, the loading after the actual cervical anterior fusion was limited to a 1-mm displacement. However, the plates and screws produced through this modeling seem to have practical use.

\section{CONCLUSION}

Screw head and anchor breaks occur when excessive force is applied to the screw. When excessive force is applied to the screw in the plate, stress may be concentrated at the portion where the plate and the head of the screw come into contact and fracture may occur. Therefore, it is necessary to partially strengthen the relatively weak biodegradable materials before use.

\section{- Acknowledgements}

This work was supported by the Industrial Core Technology Development Program (10052732) funded by the Ministry of Trade, Industry and Energy (MOTIE, Korea)

\section{REFERENCES}

1. Angevine PD, Arons RR, McCormick PC: National and regional rates and variation of cervical discectomy with and without anterior fusion, 1990-1999. Spine (Phila Pa 1976) 28:931-939; discussion 940, 2003

2. Aryan HE, Lu DC, Acosta FL, Jr., Hartl R, McCormick PW, Ames CP: Bioabsorbable anterior cervical plating: Initial multicenter clinical and radiographic experience. Spine (Phila Pa 1976) 
32:1084-1088, 2007

3. Brkaric M, Baker KC, Israel R, Harding T, Montgomery DM, Herkowitz HN: Early failure of bioabsorbable anterior cervical fusion plates: Case report and failure analysis. J Spinal Disord Tech 20:248-254, 2007

4. Cao L, Duan PG, Li XL, Yuan FL, Zhao MD, Che W, et al.: Biomechanical stability of a bioabsorbable self-retaining polylactic acid/nano-sized beta-tricalcium phosphate cervical spine interbody fusion device in single-level anterior cervical discectomy and fusion sheep models. Int J Nanomedicine 7:5875-5880, 2012

5. Chen M, Yang S, Yang C, Xu W, Ye S, Wang J, et al.: Outcomes observed during a 1-year clinical and radiographic follow-up of patients treated for 1- or 2-level cervical degenerative disease using a biodegradable anterior cervical plate. J Neurosurg Spine 25:205-212, 2016

6. Devocht JW, Goel VK, Zeitler DL, Lew D: Experimental validation of a finite element model of the temporomandibular joint. J Oral Maxillofac Surg 59:775-778, 2001

7. Fountas KN, Kapsalaki EZ, Nikolakakos LG, Smisson HF, Johnston KW, Grigorian AA, et al.: Anterior cervical discectomy and fusion associated complications. Spine (Phila Pa 1976) 32:23102317, 2007

8. Jamshidian M, Tehrany EA, Imran M, Jacquot M, Desobry S: Poly-lactic acid: Production, applications, nanocomposites, and release studies. Comprehensive Reviews in Food Science and Food Safety 9:552-571, 2010

9. Lebl DR, Bono CM, Metkar US, Grottkau BE, Wood KB: Bioabsorbable anterior cervical plate fixation for single-level degene- rative disorders: Early clinical and radiographic experience. Spine J 11:1002-1008, 2011

10. Mackiewicz A, Banach M, Denisiewicz A, Bedzinski R: Comparative studies of cervical spine anterior stabilization systems--finite element analysis. Clin Biomech (Bristol, Avon) 32:72-79, 2016

11. Meyer F, Bourdet N, Deck C, Willinger R, Raul JS: Human neck finite element model development and validation against original experimental data. Stapp Car Crash J 48:177-206, 2004

12. Shriver MF, Lewis DJ, Kshettry VR, Rosenbaum BP, Benzel EC, Mroz TE: Dysphagia rates after anterior cervical diskectomy and fusion: A systematic review and meta-analysis. Global Spine J 7:95-103, 2017

13. Smith GA, Pace J, Corriveau M, Lee S, Mroz TE, Nassr A, et al.: Incidence and outcomes of acute implant extrusion following anterior cervical spine surgery. Global Spine J 7:40S-45S, 2017

14. Song W, Zhou D, He Y: The biomechanical advantages of bilateral lumbo-iliac fixation in unilateral comminuted sacral fractures without sacroiliac screw safe channel: A finite element analysis. Medicine (Baltimore) 95:e5026, 2016

15. Stein MI, Nayak AN, Gaskins RB, 3rd, Cabezas AF, Santoni BG, Castellvi AE: Biomechanics of an integrated interbody device versus acdf anterior locking plate in a single-level cervical spine fusion construct. Spine J 14:128-136, 2014

16. Tomasino A, Gebhard H, Parikh K, Wess C, Hartl R: Bioabsorbable instrumentation for single-level cervical degenerative disc disease: A radiological and clinical outcome study. J Neurosurg Spine 11:529-537, 2009 